\title{
State of the art of ice core annual layer dating
}

Sune O. Rasmussen, A. Svensson and M. Winstrup

\section{Polar ice cores reveal past climate change in ever-growing temporal resolution. Novel automated methods and improved manual annual layer identification allow for bipolar year-to-year investigations of climate events tens of thousands of years back in time.}

Ice cores from Antarctica, from the Greenland ice sheet, and from a number of smaller glaciers around the world yield a wealth of information on past climates and environments including unique records of past temperatures, atmospheric composition (for example greenhouse gasses), volcanism, solar activity, dustiness, and biomass burning. Some ice-core records from Antarctica extend back in time more than 800,000 years (Jouzel et al. 2007), while ice cores from sites with higher accumulation offer continuous records of very high temporal resolution. For example, Greenland ice-core records reach back into the penultimate interglacial 130,000 years ago with annual or close to annual resolution (NEEM community members 2013).

To maximize the knowledge gain from ice cores it is essential to establish accurate and precise chronologies that assign an age to each depth segment. A key property of high-resolution icecore records is annual layering, which allows for the construction of a very accurate chronology by counting layers back as far as tens of thousands of years. New high-resolution measurements and improved algorithms for automated and objective annual layer counting are currently being developed to allow refinement and extension of these chronologies.

\section{Annual layering in ice cores}

Seasonal variations in isotopic composition and impurity content of the snowfall provide the basis for a distinct annual signal in the snowpack, which may be preserved in the ice under favorable conditions. The ability of an ice core to provide (sub-)annual information depends on the accumulation rate. It typically ranges from a few centimeters of ice per year in high-elevation areas of Antarctica to several meters at coastal sites of Greenland and on low latitude glaciers. In the upper part of an ice sheet, snow slowly compacts into incompressible ice. Due to the continuous accumulation of snow, annual layers become buried in the ice sheet over time. Gravity causes the ice to flow toward the ice sheet margins, which results in thinning of the annual layers with depth (Fig.

1). Close to the base of an ice sheet, ice flow over bedrock undulations causes folding and shearing leading to stratigraphic disturbances that can complicate precise dating of the lowermost section of an ice core.

\section{Detecting the annual signal}

The ratios of stable oxygen and hydrogen isotopes in glacier ice (expressed as $\delta^{18} \mathrm{O}$ and $\delta D$ values) reflect seasonal variations in local temperature at the time of precipitation (Dansgaard 1964). In ice cores from
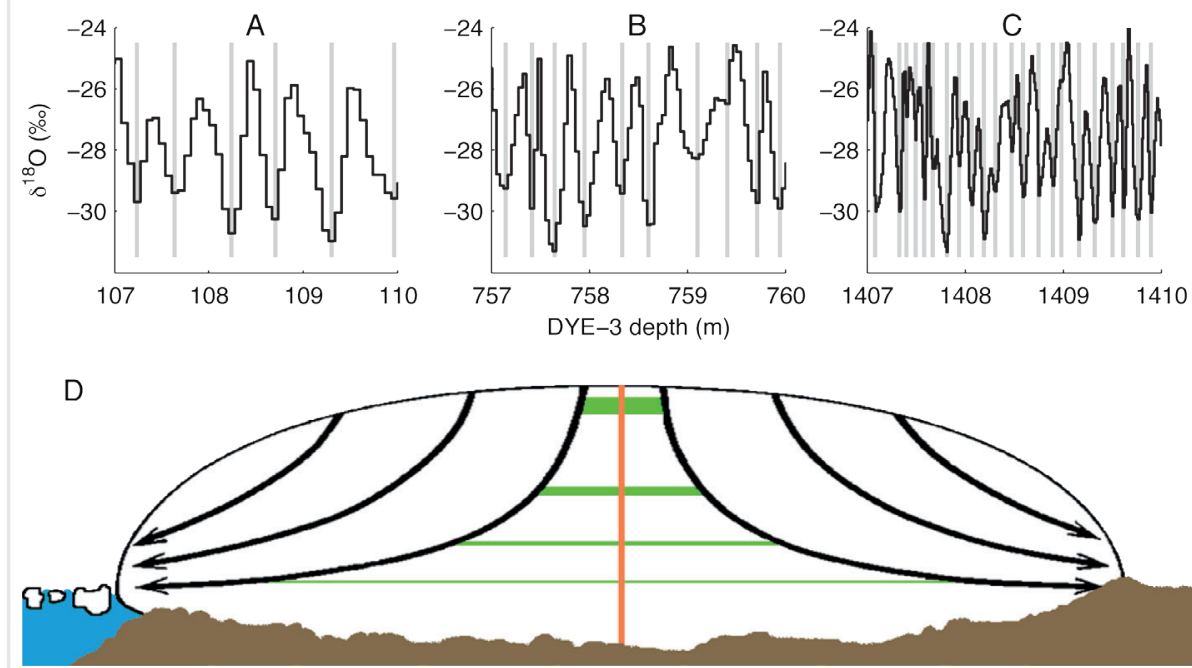

Figure 1: Three 3-meter long sections (A-C) of annually resolved $\delta^{18} \mathrm{O}$ data from different depths of the $2,037 \mathrm{~m}$ long South Greenland DYE-3 ice core. The ages are (A) 175-180, (B) 1845-1854, and (C) 4657-4678 years before A.D. 2000 , respectively. Gray bars show manually identified winter minima. (D) The ice flow leads to annual layer thinning that together with diffusion ultimately leads to a loss of the annual signal with depth.

high accumulation sites, such as the South Greenland DYE-3 core (Fig. 1), the seasonal signal may be traced 8,000 years back in time (Vinther et al. 2006). However, at lower accumulation sites, diffusion of water molecules during the transition from snow to ice reduces, or completely erases, the amplitude of the seasonal cycle. Moreover, ice flow-induced layer thinning and diffusion of water molecules within the deep ice ultimately obliterates the seasonal $\delta^{18} \mathrm{O}$ and $\delta D$ cycles even in high-accumulation areas (Johnsen et al. 2000). Therefore, in deeper ice, other proxies less prone to diffusion must be employed for annual layer detection.

An annual signal may also be preserved in the impurity content of an ice core, as many impurities display a seasonal variation (Fig. 2). In Greenland, for example, dust concentrations generally reach a maximum during spring, whereas the amount of sea-salt aerosols peaks during winter (Rasmussen et al. 2006). The annual dust cycle can sometimes be identified from the visible layering of an ice core (Svensson et al. 2005), but most impurity records are obtained by measurements on melted samples, often using a melting device and a high-resolution continuous flow analysis (CFA) system (Röthlisberger et al. 2000).

\section{Counting of annual layers}

In general, impurity records are more complex to interpret than isotope records as they also contain non-annual signatures, e.g. input from volcanic eruptions, biomass burning, and other episodic sources. For this reason, the parallel analysis of several impurity records of different origin is recommended when establishing a chronology. Extensive high-resolution CFA datasets have allowed for manual multi-proxy layer identification in ice cores from both hemispheres. In Greenland, data from several cores form the basis of the Greenland Ice Core Chronology 2005 (GICC05), which extends 60,000 years back in time (Svensson et al. 2008). Annual layers have also been identified back to $\sim 30,000$ years BP in the ice core drilled on the West Antarctic Ice Sheet Divide (WAIS Divide Project Members 2013), in the Antarctic EPICA Dronning Maud Land ice core (EDML), and in numerous younger ice cores from both hemispheres. These ice-core chronologies rely on manually identifying annual layers, which is laborious and inherently entails subjectivity. However, it is also a very flexible approach that 


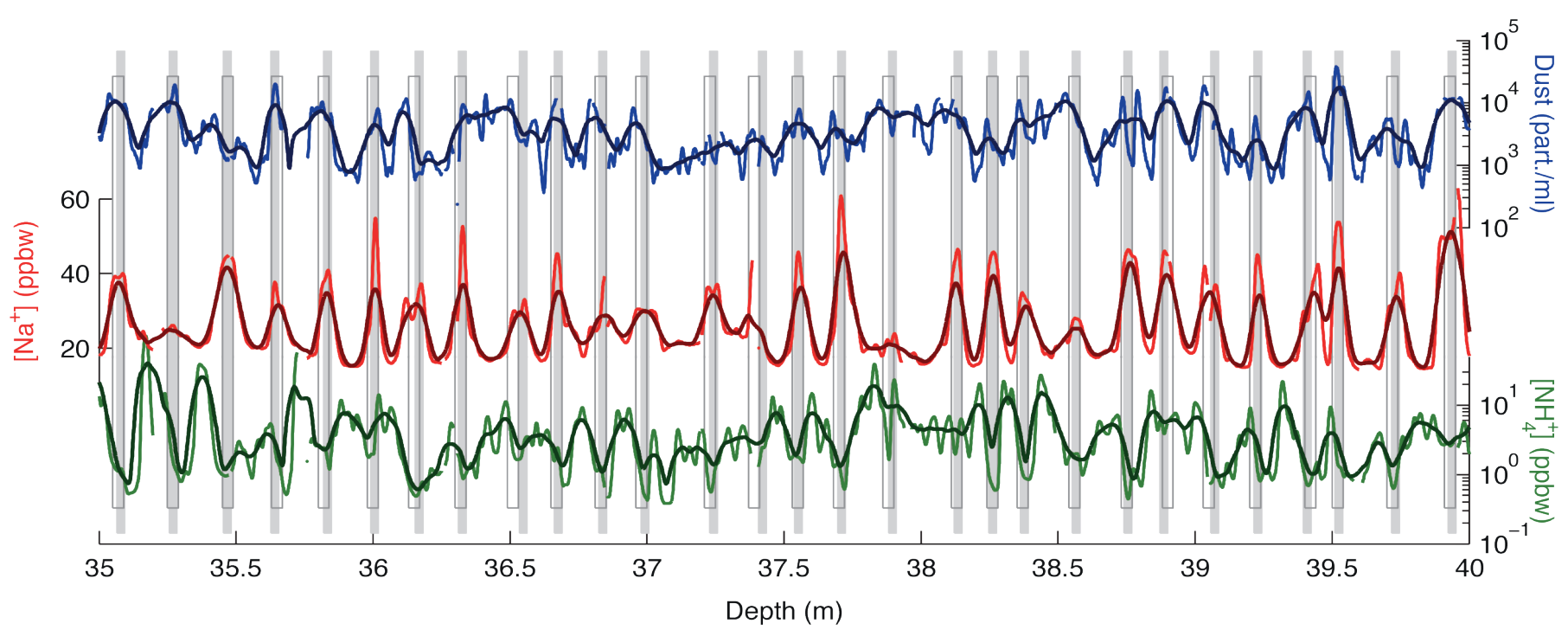

Figure 2: Example of continuous flow analysis data (smoothed curves in bold) from a shallow ice core from the North East Greenland Ice Stream (NEGIS) site. Several different impurities are measured, but here we show only the concentration of insoluble dust, Sodium ions, and Ammonium ions, chosen because the annual signal is expressed in different ways in these three data series. Manually identified winter layers (grey solid bars) and automated dating results (open gray bars; for method see Winstrup et al. 2012) agree in sections where the annual signal is clearly expressed in all three data series with a resolution sufficient to resolve even relatively thin layers.

can accommodate changes in the expression of annual layers, data quality, and resolution.

\section{Development of new methods}

New analytical techniques are widening the array of impurities that can be analyzed at annual resolution (McConnell et al. 2002). Moreover, refinement of CFA setups and data processing is increasing data resolution, now allowing detection of strata at the millimeter scale (Bigler et al. 2011). The resulting improvements in data quality and quantity allow for the extension and improvement of current ice-core chronologies as annual layers can now be detected in sections of the cores where annual layer identification has not previously been possible. Furthermore, development of new methods for statistical annual layer detection may soon supplement manual layer identification. Several automated approaches are being developed and have been applied to both single-record and multi-parameter data sets (Winstrup et al. 2012; Wheatley et al. 2012; McGwire et al. 2011). Among the more sophisticated approaches, the Bayesian algorithm by Winstrup et al. (2012) considers all possible divisions of a data series into an arbitrary number of layers, and selects the optimal division based on the appearance of layers and their individual thicknesses (Fig. 2). The method relies on assumptions of the statistical nature of the annual signal, the validity of which should be tested where independent dating methods allow for this. Providing that these assumptions are correct, the automated method produces objective annual layer-based ice-core chronologies with well-quantified uncertainties. Integrated uncertainty estimation is a key quality of this automated Bayesian method that represents a significant advance compared with manual subjective error estimates.

\section{The accuracy-precision issue and new} common chronological frameworks

As with any annually laminated record dated by layer counting, the uncertainty accumulates with increasing age. Consequently, the determination of absolute ages is very accurate for recent periods, while the accumulated uncertainty often becomes large (i.e. low accuracy) compared to e.g. radiometric dating uncertainties in the last glacial period. However, even when the absolute accuracy is relatively low, layer counting still provides the possibility to determine event durations as recorded in the ice cores very precisely. For example, the accuracy of the GICC05 time scale at the onset of the Holocene is about a century, while the outstanding precision allows for the analysis of how the transition into the Holocene is expressed in different proxy records with a maximum relative dating error of only a few years (Steffensen et al. 2008). In a similar way, the GICC05 counting uncertainty of a few percent in the glacial period makes it possible to constrain the duration of interstadial 11 in the Greenland record to 1100 years with a maximum counting error of just 54 years (high precision). In contrast, the absolute age of the event (43 ka before present) has a rather low accuracy due to an accumulated maximum counting error of 1700 years.

Ice cores from different sites can be synchronized using common time marker horizons of, for example, volcanic origin (Rasmussen et al. 2008; Severi et al. 2007; Parrenin et al. 2012) or common variations in methane levels (Blunier and Brook 2001; Pedro et al. 2011). Hence records from different sites can be aligned for parallel analysis with a precision that is often several orders of magnitude better than the absolute dating accuracy. Following this approach, the GICC05 chronology is currently being applied to all main Greenland ice cores to allow analysis of the climatic information from all cores in a consistent chronological framework. Recent studies also have employed a set of global event markers to synchronize ice cores from both hemispheres (Raisbeck et al. 2007; Svensson et al. 2013; Sigl et al. 2013) and are incorporating other sources of dating and ice flow information in a modeling framework in order to construct a consistent multi-ice-core chronology (Lemieux-Dudon et al. 2010). The fidelity of chronologies modeled that way increases with the addition of more data and better quantification of the entailing uncertainties (Veres et al. 2013; Bazin et al. 2013). However, annual layer counted sections have yet to be included in a way that respects the nature of the annual layer counting process and the involved uncertainty. Therefore, modeled chronologies following this approach must still be considered complementary to annual layer counted chronologies.

Experimental and analytic innovations keep pushing the construction of annual-scale ice-core chronologies forward. Upcoming developments may allow stratigraphic ice-core chronologies to reach further back in time, to reduce and better quantify uncertainties, and to become better integrated both regionally and on a global scale.

\section{AFFILIATIONS}

Centre for Ice and Climate, Niels Bohr Institute, University of Copenhagen, Denmark

\section{CONTACT}

Sune O. Rasmussen: olander@gfy.ku.dk

\section{REFERENCES}

\section{Full reference list under:}

\section{http://www.pages-igbp.org/products/newsletters/} ref2014_1.pdf

Bazin L et al. (2013) Clim Past 9: 1715-1731

Bigler M et al. (2011) Environ Sci Technol 45: 4483-4489 Sigl M et al. (2013) J Geophys Res [Atmos] 118: 1151-1169 Svensson A et al. (2013) Clim Past 9: 749-766

Winstrup M et al. (2012) Clim Past 8: 1881-1895 